\title{
O Estado em desmonte frente à epidemia da Covid-19
}

\author{
$\mid{ }^{1}$ Nercilene Monteiro | \\ ${ }^{1}$ Fundação Oswaldo Cruz. Rio de Janeiro-RJ, Brasil (nercilene.monteiro@fiocruz.br). ORCID: 0000-0002-1785-7022 \\ Recebido em: 10/06/2020 \\ Aprovado em: 14/06/2020 \\ Revisado em: 20/06/2020
}

DOI: http://dx.doi.org/10.1590/S0103-73312020300304

\section{A falta de solidariedade global marca a primeira pandemia do século XXI}

Em 30 de dezembro de 2019, a China comunicou à Organização Mundial da Saúde (OMS) o aumento atípico dos casos de pneumonia na província de Wuhan. Na semana seguinte, autoridades chinesas identificaram um novo tipo de coronavírus, uma cepa ainda não notificada em humanos. No mesmo mês, a OMS declarou Emergência de Saúde Pública de Importância Internacional (ESPII), ${ }^{1}$ alertando as autoridades sobre os riscos do novo coronavírus (PHO, 2020). O objetivo era iniciar a coordenação, a cooperação e a solidariedade mundial diante do alto risco de propagação da doença. No entanto, ao contrário de uma rede de proteção, formou-se uma guerra comercial por equipamentos de proteção individual (EPI), respiradores, testes e medicamentos produzidos pela China, evidenciando vulnerabilidades não só dos países periféricos, mas de todo o mundo desenvolvido.

O desabastecimento interno de insumos para enfrentar a epidemia na Europa e nos Estados Unidos revelou alta dependência de produtos vindos da Ásia, escancarando a concentração da produção de bens essenciais fora do controle dessas 
potências, apesar de todo domínio tecnológico e dos fabulosos parques produtivos que possuem. A solução capitalista para o problema foi a adoção de bloqueios de exportação, retenção e até pirataria de cargas compradas por outros países.

A dependência de insumos é consequência da divisão internacional do trabalho que concentra o acesso a tecnologias e a produção em algumas regiôes do mundo. Nessa divisão, para a América Latina (AL) foi designado o papel de fornecedor de produtos básicos para as economias centrais, e mesmo países com bom nível de industrialização como o Brasil, enfrentam imensas dificuldades para desenvolver suas políticas internas, quando estas dependem de um grande volume de insumos importados, como é o caso do Sistema Único de Saúde (SUS), cuja dependência já chega a 94\%, conforme ressalta Gadelha (2020). Portanto, a crise de desabastecimento que o mundo enfrentou é praticamente permanente quando se trata do Brasil.

Além da dependência de produtos importados, o SUS é também dependente do setor privado. Segundo Dourado (2013), 72,4\% dos leitos estão nas mãos de entes privados e praticamente toda rede de exames é privatizada, correspondendo a $90 \%$ dos Serviços de Apoio Diagnóstico e Terapêutico (SADT).

Este texto tem o objetivo de se somar a outros que alertam sobre a impossibilidade de desenvolver adequadamente o SUS sem compreender e encontrar saídas para os obstáculos estruturais que estão colocados para o Estado brasileiro desde sua inserção como economia dependente no sistema capitalista, ${ }^{2}$ assim como refletir sobre o conjunto de medidas de desmonte do Estado adotadas com a mesma finalidade, ou seja, subjugar os Estados nacionais aos interesses de expansão das atividades privadas.

\section{O processo de desmonte do Estado brasileiro}

No Brasil, a primeira contaminação confirmada foi a de um homem de 61 anos que havia voltado da Itália. O homem se recuperou no Hospital Israelita Albert Einstein em março, no mesmo mês em que ocorreram as primeiras mortes pela Covid-19. Uma delas foi da doméstica de 63 anos, cuja patroa também havia voltado recentemente da Itália. A doméstica saiu do trabalho diretamente para a unidade de saúde, já em estado grave, falecendo no Hospital Municipal Luiz Gonzaga.

A epidemia evidencia a violência da desigualdade e mostra que, apesar de o vírus contaminar ricos e pobres, a diferença de classe social tem sido determinante para a 
recuperação ou a morte. Curran (2013) aponta que diante de qualquer situação, até mesmo de catástrofes naturais, os mais ricos têm condiçóes para superar adversidades e realizar novas opçóes no futuro, enquanto os pobres permanecem se confrontando com as consequências de sua situação social. Os riscos sociais têm sido crescentes no Brasil, como violência e desemprego, impactando especialmente as famílias chefiadas por mulheres (RODRIGUES; SANTOS, 2017).

A natureza desses riscos está relacionada com as condiçóes de vida mediadas pela provisão, ou pela carência de alimentação, moradia, trabalho, saúde, educação, segurança e lazer. No campo da saúde, o SUS tem sido fundamental para a mitigação de parte desses riscos; no entanto, como destaca Tubero (2011), o sistema sofre com a subordinação do Estado ao mercado. Essa subordinação está relacionada com as medidas neoliberais da década de 1980 (Consenso de Washington) e que basicamente determinam a reduçáo do papel do Estado para que a iniciativa privada possa ampliar seu espaço de atuação.

Segundo Rodrigues (2003), as ideias neoliberais ameaçaram os regimes de Welfare State, mas não foram capazes de implementar mudanças estruturais. Isto é verdade, no entanto é notável que o avanço do mercado sobre os regimes de Welfare permanece buscando novas formas de se desenvolver e expandir atividades privadas no interior desses.

Ao analisar a Reforma de Estado realizada em 1995 no Brasil, podemos observar que o objetivo não foi desestimular políticas internas, mas substituir sua natureza "improdutiva" por meio de privatizaçôes, terceirizaçôes e publicizaçôes.

Dourado (2013) ressalta que as transformaçôes dos sistemas de saúde no período de 1970-80 caminhavam para uma expansão do capital que percebeu, no setor público, a possibilidade de escapar das crises econômicas, fornecendo bens e serviços no lugar do Estado. Isto fica evidente quando se analisa o Caderno n. 13, que traçava a reforma do setor saúde (BRASIL, 1998). O documento relatava a visita à Inglaterra do entáo ministro Bresser Pereira e seu encantamento com as reformas feitas no National Health Service (NHS). Como anexo ao caderno, foi inserida uma matéria publicada no The Economist, que podemos resumir na defesa de sistemas de saúde universais, porém não estatais.

A proposta para área da saúde era a de que os serviços passassem a ser operados por organizaçóes sociais, na chamada publicização, adotando-se modelos de desempenho e custos originários na iniciativa privada. 
Em maio de 1998, foi editada a Lei n. 9.637, qualificando entidades como organizações sociais (OS) e criando o Programa Nacional de Publicização. Em março de 1999 foi editada a Lei n. 9.790, qualificando pessoas jurídicas de direito privado sem fins lucrativos como organização da sociedade civil de interesse público (OSCIP). Segundo dados do IPEA (2018), entre 1981 e 1990 o Brasil tinha 88.147 organizações dessa natureza, mas depois da edição dessas duas leis, foram criadas mais 478.841 OS. Atualmente são 820.186 organizações da sociedade civil, ${ }^{3}$ e dentre essas, $6.841 \mathrm{administram} \mathrm{hospitais} \mathrm{e} \mathrm{unidades} \mathrm{de} \mathrm{saúde} \mathrm{pelo} \mathrm{Brasil.} \mathrm{Embora} \mathrm{seja} \mathrm{um}$ quantitativo pequeno em relação ao universo total, é no campo da saúde que está o maior volume financeiro e também a maior quantidade de empregos formais, totalizando 112.048 postos de trabalho, dentre os quais médicos, enfermeiros, técnicos e agentes comunitários de saúde.

É fundamental notar que no mesmo período de maior criação das OS, acontecia a expansão dos serviços de saúde por meio da NOB 96, que determinou formas e incentivos para descentralização dos serviços de saúde para estados e municípios. Exatamente cinco anos depois dessa NOB, foi editada a Lei de Responsabilidade Fiscal, ${ }^{4}$ que limitou a contrataçáo de pessoal pela União, estados e munícipios, criando o paradoxo em que os estados e municípios foram encarregados de prestar serviços de saúde, quase ao mesmo tempo em que foram impedidos de prestar tais serviços diretamente à população.

O objetivo declarado da LRF era evitar o endividamento dos estados; no entanto, a possibilidade de contrataçáo das OS como prestadores de serviços criou as condiçôes para desenvolver as açôes de saúde e endividou os estados com custos ainda maiores decorrentes de encargos contratuais. $\mathrm{Na}$ realidade, a LRF não evita o endividamento dos estados, tanto assim que em 2017 foi editada a Lei de Recuperação Fiscal dos Estados (Lei Complementar n. 159/2017). Ela serve para manter quadros precarizados no serviço público e para ser usada como manobra para afastar governantes, quando algum tribunal, milagrosamente, percebe que a contratação das OS constitui fraude à LRF. Portanto, a Reforma do Estado de 1995 e a LRF foram as principais responsáveis pela precarização do trabalho no âmbito do SUS, mas não parou por aí. Podemos dizer que o ano de 2016 inaugurou medidas de austeridade aviltantes para o trabalhador brasileiro, assim como relegou ao Estado o papel da inutilidade social, tirando deste agente econômico a capacidade de reação perante crises econômicas. 
No conjunto dessas medidas está a Emenda Constitucional n. 95 que entrou em vigor em 2016 com o objetivo de congelar os gastos da União até 2036. Essa medida, de acordo com levantamento do Conselho Nacional de Saúde (2020), retirou 20 bilhões de reais do SUS em 2019. A projeção do Cebes (VIEIRA et al., 2018) é que, até 2036, o SUS sofra uma perda aproximada de 168 bilhóes de reais.

A outra medida que interfere diretamente na capacidade de gestão do Estado foi a reforma trabalhista realizada em 2017. Esta prometia a retomada dos investimentos, com criação de novos postos de trabalho e aumento do consumo - gerando receitas para o Estado, cujos excedentes são essenciais para o desenvolvimento das políticas públicas. No entanto, tudo que produziu foi a redução da renda do trabalhador numa velocidade que praticamente anulou os ganhos dos últimos 15 anos. Atualmente a população ocupada é de 94,2 milhōes de pessoas, sendo 40,7\% compostos por trabalhadores informais e 23,2\% subutilizados (IBGE, 2020). A ampliação do mercado informal, dos intermitentes e dos subutilizados é apontada como a principal causa da perda de renda, pois boa parte desses trabalhadores não recebem auxílio alimentação, vale-transporte, $13^{\circ}$ salário, adicional de férias, abonos ou horas extras.

\section{O pandemônio da epidemia da Covid-19 no Rio de Janeiro}

Depois do dinamismo econômico, com o aumento da arrecadação dos royalties, da prospecção de um futuro promissor com o Complexo Petroquímico do Rio de Janeiro (Comperj) e dos grandes eventos internacionais - Copa do Mundo em 2014 e Jogos Olímpicos em 2016 -, o Estado do Rio de Janeiro entrou em uma espiral de debacle que parece não ter fim.

A prisão do ex-governador Sérgio Cabral, em novembro de 2016, tornou público um grande esquema de corrupção sob sua liderança, que envolvia boa parte de seu secretariado e empresários que mantinham atividades relevantes no estado. A magnitude dos crimes afastou investidores, suspendeu contratos públicos e privados e resultou na maior taxa de desemprego nacional, saindo de $6,5 \%$ no final de 2014 para 13,4\% no final de 2016 (IBGE, 2020). O desemprego empurrou milhares de pessoas para a informalidade, resultando em perda de direitos, renda e consequentemente, perda da capacidade de consumo.

Essa crise trouxe sérias repercussôes sobre os serviços públicos, que sofreram interrupção em 2017, devido aos sucessivos atrasos de pagamento dos servidores e 
fornecedores. O estado também sofreu com o aumento dos índices de desemprego e de violência, e a prisão do presidente da Assembleia Legislativa - Jorge Picciani - criou um ambiente de vácuo político que favoreceu a eleição, para governador, do ex-juiz Wilson Witzel, em 2018, com uma agenda de combate à corrupção e abate de bandidos, e de Marcelo Crivella, para prefeito da capital, com uma agenda conservadora - ambos com uma pauta comum de redução do papel do Estado.

O efeito da gestáo dessas pessoas - que serve perfeitamente ao projeto de desmonte do Estado, tem sido uma baixa capacidade de resposta do sistema de saúde, mesmo tendo ampla rede assistencial no Estado do Rio de Janeiro. Segundo dados da Secretaria Estadual de Saúde, o SUS atende 67,34\% da população do Rio de Janeiro, correspondendo a 11.261.149 pessoas. A capacidade instalada é uma das maiores do Brasil, com 21.967 leitos do SUS em diversas especialidades. A gestáo desses leitos é compartilhada, sendo 3.328 de gestão federal, 3.267 de gestão estadual, 9.254 de gestão municipal, 2.315 público-privados e 3.803 leitos em instituiçôes sem fins lucrativos.

Sob a gestão do Estado do Rio de Janeiro estáo 56 unidades de saúde, sendo 26 hospitais e 30 Unidades de Pronto Atendimento (UPAs). Os mais de três mil leitos são gerenciados pela Secretaria Estadual de Saúde, e a execução dos serviços é delegada a OS (11), Fundação Estadual de Saúde (10), convênios público-privados (3) e administração direta (2).

Durante a epidemia de Covid-19 ficou muito claro que, mesmo em estados com ampla estrutura assistencial, a separação entre a gestáo e operacionalizaçáo de serviços não apresenta bom desempenho. É ilustrativo o caso da OS criada em 2008, quando a Atenção Básica se ampliava no Rio de Janeiro - o Instituto de Atenção Básica e Avançada à Saúde (IABAS). Durante a pandemia, o IABAS foi contratado para instalar sete hospitais de campanha e não entregou nenhum dentro do prazo pactuado. $\mathrm{O}$ único que entregou apresenta precariedades de instalação noticiadas pela imprensa. Do ponto de vista da força de trabalho, esse tipo de organização tem se especializado em contratar da forma mais precária possível, tomando por base as novas regras da Reforma Trabalhista de 2017. Os profissionais são contratados para atuar na linha de frente sem treinamento e EPI adequados, e não têm garantias em caso de infecção pelo vírus, pois são contratados como pessoas jurídicas, cooperativados ou até mesmo por meio de pagamento direto sem contrato.

Na gestão municipal, o quadro não é diferente. Apesar de o slogan de campanha do prefeito ter sido "cuidar das pessoas", o gestor, sob alegação da crise financeira, 
apresentou o Plano de Reorganização dos Serviços de Atenção Primária, cujo único resultado até o momento foi o fechamento de clínicas da família e a demissão de mais de 1.400 profissionais de saúde.

O desmonte do Estado tem acontecido gradual e sistematicamente, a partir de uma agenda dedicada a substituir a prestaçấo pública de serviços considerados "improdutivos" porque não geram lucros por atividades prestadas pela iniciativa privada. Por isso, cada vez mais os liberais se posicionam em defesa do SUS, mas tudo leva a crer que isto não se deve à conversão ao pensamento igualitário, sendo mais provável que estejam agindo na defesa de interesses capitalistas. Esses interesses têm sido alcançados pelas medidas descritas neste texto e que, desde a década de 1990, vêm colaborando para a expansão cada vez maior das atividades privadas no interior dos serviços públicos, seja prestando serviços que o Estado poderia prestar diretamente, seja vendendo serviços de internação e exames, seja atuando para incorporação e venda de tecnologias altamente discutíveis.

É muito importante que a militância da saúde coletiva compreenda que o setor saúde está inserido em um nicho econômico de alta demanda tecnológica e agressivas estratégias competitivas ditadas por um mercado que vem submetendo o Estado brasileiro desde a implantação do SUS.

Há ainda tendências de novas complicações, como aponta Filippon (2015). Em seu estudo sobre a abertura do mercado privado da saúde no Brasil (Lei n. 13.097/2015), o autor destaca que empresas estrangeiras estudam o mercado brasileiro há muito tempo e que a vedação de investimentos estrangeiros na prestação de serviços de saúde dificultava a entrada de capital. Com a aprovaçáo dessa lei, o primeiro e o segundo estágio de dominação de mercado no Brasil estão em curso, com a compra e a fusão de prestadores de serviços privados. De acordo com Filippon, na terceira fase, os grandes players se estabelecem, recuperam os prejuízos das fases anteriores e passam a regular a oferta.

Neste momento, acontece o aumento de preço e a maior segmentação do mercado. Com um SUS altamente dependente de serviços privados, o Estado ficará de joelhos perante a exploração privada e a tendência é sucumbir, perdendo a capacidade nos níveis secundários e terciários, nos quais o capital vai se concentrar em busca de maior lucratividade, limitando a oferta pública aos cuidados básicos com os pobres e assistindo a exploração desmedida das classes média e alta. 


\section{Referências}

BRASIL. Emenda Constitucional n. 95, de 2016. Altera o Ato das Disposiçóes Constitucionais Transitórias, para instituir o Novo Regime Fiscal, e dá outras providências. Brasília, 2016a. Disponível em:<https://www.planalto.gov.br/ccivil_03/constituicao/Emendas/Emc/emc95. htm>. Acesso em: 7 jun. 2020.

. Ministério da Administração Federal e Reforma do Estado. A Reforma administrativa do sistema de saúde. Brasília: MARE, 1998.

VIEIRA, F. S. et al. Políticas sociais e austeridade fiscal: como as políticas sociais são afetadas pelo austericídio da agenda neoliberal no Brasil e no mundo. Rio de Janeiro: CEBES, 2018.

CONSELHO NACIONAL DE SAÚDE. Saúde perdeu R \$ 20 bilhóes em 2019 por causa da EC 95/2016. Disponível em: https://conselho.saude.gov.br/. Acesso em: 8 jun. 2020.

CURRAN, D. What is a critical theory of the risk society? A reply to Beck. The British Journal of Sociology, v. 64, p. 75-80, 2013.

DOURADO, V. V. Como o sistema de saúde brasileiro contribui para a manutenção e reprodução do Capital? Campinas: Faculdade de Ciências Médicas/Unicamp, 2013.

FILIPPON, J. A abertura da saúde nacional ao capital estrangeiro: efeitos do mercado global no Brasil. Saúde em debate, v. 39, p. 1127-1137, 2015.

GADELHA, C. G. Não podemos ter um SUS com tamanha dependência. O Globo, Rio de Janeiro, 12 abr.2020.

INSTITUTO BRASILEIRO DE GEOGRAFIA E ESTATÍSTICA. Taxa de Desocupação é de $11,2 \%$ e taxa de subutilização é de $23,2 \%$ no trimestre encerrado em janeiro de 2020 . Agência de Notícia, 28 fev. 2020. Disponível em: https://agenciadenoticias.ibge.gov.br. Acesso: 28 mar. 2020.

ORGANIZAÇÃO PAN-AMERICANA DE SAÚDE NO BRASIL. Folha Informativa Covid-https://www.paho.org/bra/index.php?option=com_content\&view=article\&id=6101:cov id19\&Itemid=875\#historico. Acessado em: 6 jun. 2020.

RODRIGUES, P. H. Apocalipse não: o Estado do bem-estar social sobrevive à onda neoliberal. Tese (Doutorado) - Universidade do Estado do Rio de Janeiro, Instituto de Medicina Social, Rio de Janeiro, 2003.

. Os novos riscos sociais não só europeus, também chegaram ao Brasil e exigem respostas das nossas políticas sociais. In: RODRIGUES, P. H.; SANTOS, I. S. (Orgs.). Políticas e riscos sociais no Brasil e na Europa: convergências e divergências. Rio de Janeiro: Cebes; São Paulo: Hucitec Editora, 2017. p. 111-141. 
SECRETARIA ESTADUAL DE SAÚDE (RIO DE JANEIRO). Plano Estadual de Saúde. Rio de Janeiro 2020-2023. Governo do Estado do Rio de Janeiro, 2019.

TUBERO, T. Z. Movimento sanitário: o SUS, debates e críticas. Campinas: Faculdade de Ciências Médicas/Unicamp, 2011.

\section{Notas}

${ }^{1}$ Esse é o maior nível de alerta sanitário emitido pela OMS e o sexto em sua história recente: H1N1 (2009), poliovírus (2014), ebola (2014), zika (2016), ebola (2018) e coronavírus (2020).

${ }^{2}$ A Teoria Marxista da Dependência se dedica a refletir sobre o processo de desenvolvimento econômico da América Latina a partir de sua formaçáo histórica e dos condicionantes estruturais estabelecidos desde sua entrada no sistema capitalista. Esses condicionantes podem ser resumidos como a manutenção de uma base agroexportadora para economias centrais, remessa de lucros e ganhos derivados de propriedade intelectual para essas economias, entre outras medidas que têm ampliado as vantagens dos países dominantes sobre a regiáo, com repercussóes negativas para as economias internas e para o trabalhador latino-americano. São expoentes relevantes dessa teoria: Prebisch, Rui Marine, Theotônio dos Santos, Vânia Bambirra, Mathias Luce, entre outros que se dedicam a estudar o capitalismo dependente da América Latina.

${ }^{3}$ Organizações sociais qualificadas pela Lei n. 9.637/1998, associaçóes privadas, fundaçôes privadas e organizaçôes religiosas de direito privado sem fins lucrativos previstas no Código Civil - Lei n. 10.406/2002, ou organizaçôes religiosas reconhecidas a partir da Lei n. 10.825/2003

${ }^{4}$ A Lei n. 101/2001 limita a contratação direta de pessoal em até 50\% da receita líquida da União, e em até $60 \%$ da receita líquida de estados e municípios. 